\title{
Antioxidant and anti-inflammatory effects of selenium in oral buccal mucosa and small intestinal mucosa during intestinal ischemia-reperfusion injury
}

\author{
Yongsoo Kim', Dong Chil Kim ${ }^{1}$, Eui-Sic Cho ${ }^{1}$, Seung-O Ko ${ }^{1}$, Woon Yong Kwon², Gil Joon Suh²*
} and Hyo-Keun Shin ${ }^{1 *}$

\begin{abstract}
Background: The aim of this study were to investigate whether selenium treatment attenuates lipid peroxidation and downregulates the NF-KB pathway in small intestinal mucosa and to examine whether the effect of selenium is also observed in oral buccal mucosa, during small intestinal IR injury.

Materials and methods: Eighteen rats were assigned into three groups: sham, IR, and IR + selenium. Saline or selenium was administered through a tail vein. 24 hours later, the superior mesenteric artery was exposed and clamped in the IR and IR + selenium groups. After ischemic and reperfusion period, animals were sacrificed and oral buccal mucosa and small intestinal mucosa were harvested.

Results: Glutathione peroxidase activity and cytoplasmic IKB-a expression was higher in the IR + selenium group than that in the IR group. A malondialdehyde level, cytoplasmic phosphorylated inhibitor kB-a, nuclear NF-kB p65 expressions, and NF-KB p65 DNA-binding activity were lower in the IR + selenium group than those in the IR group.

Conclusion: A selenium treatment may cause increased GPx activity, attenuated lipid peroxidation, and downregulated the NF-kB pathway during small intestinal IR injury. Furthermore, these therapeutic benefits of selenium can be observed in oral buccal mucosa as well as small intestinal mucosa.
\end{abstract}

Keywords: Ischemia reperfusion injury, Selenium, Lipid peroxidation, NF kappaB, Buccal mucosa, Small intestine

\section{Introduction}

When the blood supply diminishes in metabolically active tissues, the tissue ischemia results in the so-called ischemic injury. Subsequently, when the blood flow restores, the reperfusion injury also occurs. This reperfusion injury can damage the affected tissues more seriously than the ischemic injury [1]. The development of reperfusion injury is mediated by reactive oxygen species (ROS) formation, lipid peroxidation, and inflammatory responses [2].

\footnotetext{
* Correspondence: suhgil@snu.ac.kr; omfs@chonbuk.ac.kr

${ }^{2}$ Department of Emergency Medicine, Seoul National University College of Medicine, 101 Daehak-Ro Jongno-Gu, Seoul 110-744, Korea

'Department of Oral \& Maxillofaical Surgery, School of Dentistry and Institute of Oral Bioscience, Research Institute of Chonbuk National University

Hospital, Chonbuk National University, 664-14, Duckjindong, Chonju 561-756, Chonbuk, Korea
}

Among the internal organs, the small intestine is the most vulnerable organ to ischemia-reperfusion (IR) injury [3]. IR injury in the small intestine breaks mucosal barrier, which results in occurrence of systemic inflammatory response syndrome (SIRS). Then, SIRS can induce secondary injuries to the distant organs leading to multiple organ failure (MOF) or even to death [4]. The mechanisms of the initiation and progression of SIRS during small intestinal IR injury are ROS formation, ROS-dependent inhibitor $\kappa B-\alpha$ (IкB- $\alpha$ ) phosphorylation in cytoplasm, and subsequent nuclear factor $\kappa B(\mathrm{NF}-\kappa \mathrm{B})$ activation in nucleus. Recent in vitro studies have shown that ROS enhances cytoplasmic signaling pathways leading to NF-kB nuclear translocation [5-7]. Therefore, the antioxidant therapy can be considered as a therapeutic strategy to attenuate inflammatory responses induced by

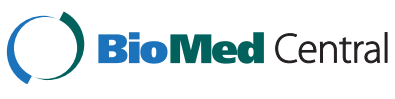


IR injury. Previous studies also reported that selenium suppressed NF-kB activation $[8,9]$.

Selenium is an essential element having antioxidant and immunomodulation function. Selenium is used to synthesize the amino acid, called selenocysteine, which is vital to the function of selenoprotein. At least, 25 selenoproteins are found in the human body and those are classified by the function into antioxidant enzymes (glutathione peroxidase, GPx), antioxidant proteins (selenoprotein $\mathrm{P}$ and $\mathrm{W}$ ), other metabolic enzymes (thioredoxin reductase and iodine deiodinase) [10]. Previous preclinical studies have reported that selenium suppresses ROS formation by increasing GPx activity [11,12]. This antioxidant effect could be responsible for the beneficial effect of selenium such as inhibition of carcinogenesis, myocardial protection in myocardial infarction, neuronal protection in focal neurological injury $[13,14]$. Furthermore, some clinical studies showed that lower selenium level was related with the increased mortality and the administration of selenium (sodium selenite, $\mathrm{Na}_{2} \mathrm{O}_{3} \mathrm{Se}$ ) has improved the survival $[15,16]$. However, there have been no in vivo studies which investigate therapeutic effects of selenium on small intestinal IR injury.

The most accurate method to determine therapeutic effects of selenium on small intestinal IR injury is to examine the small intestine itself, which is clinically very difficult. Oral buccal mucosa has the similar state of differentiation to that of the small intestinal villi and shows the decreased microvascular blood flow in distributive shock [17-19]. Furthermore, oral buccal mucosa can be easily and noninvasively accessible in clinical setting. If oral buccal and small intestinal mucosal damages during intestinal IR injury are similar, the oral buccal mucosa can be considered as a marker for the evaluation of intestinal mucosal injury. In fact, our previous study was conducted to determine the usefulness of oral buccal mucosa in the evaluation of the intestinal IRI by estimating the activation level of the NF-кB pathway of the buccal mucosa, and the result suggested a possibility of the buccal mucosa as an indicator for the assessment of intestinal ischemia-reperfusion injury [20]. Therefore, we hypothesized that selenium pretreatment would enhance GPx activity, attenuate lipid peroxidation, and downregulate the NF-кB pathway by suppression of ROS formation and subsequent ROS-dependent IKB- $\alpha$ phosphorylation during small intestinal IR injury, and that antioxidant and antiinflammatory effects of selenium would be observed in oral buccal mucosa as well as small intestinal mucosa.

The purpose of this study were to examine whether selenium pretreatment is associated with the enhancement of GPx activity, the suppression of ROS formation and subsequent ROS-dependent IкB- $\alpha$ phosphorylation, the attenuation of lipid peroxidation, and the downregulation of the NF- $\mathrm{KB}$ pathway during small intestinal IR and to investigate if antioxidant and anti-inflammatory effects of selenium are observed in oral buccal mucosa as well as small intestinal mucosa during small intestinal IR injury.

\section{Materials and methods \\ Experiment animals}

Experiments were performed on male Sprague-Dawley rats (body weight, 300 - 350 g; Orient Bio Incorporated, Seongnam, Republic of Korea). Animals were maintained on a laboratory chow (Lab Diet) and water ad libitum and housed in a specific pathogen-free room at constant temperature $\left(20-22^{\circ} \mathrm{C}\right)$ with 10 and $14 \mathrm{hrs}$ of light and dark exposure, respectively. Animals underwent an acclimatization period of 14 days before being used in experiments. All of the experiments conducted were approved by the Institutional Animal Care and Use Committee of our institute.

\section{Experimental procedure}

Subjects were divided into the 3 groups ( $\mathrm{n}=6$ in each group): the sham group, animals of which underwent a sham operation; the IR group, ischemic-reperfusion (IR) injury alone; the IR + selenium group, IR injury plus selenium infusion. Experimental procedures to induce IR injury were performed as previously described [20]. Briefly, rats were anesthetized with $100 \%$ oxygen and 3\% Isoflurane (Forane solution; Choongwae Pahrmacy, Seoul, Republic of Korea) in the rodent circuit controller. Appropriate level of anesthesia was obtained by intramuscular injection of $15 \mathrm{mg} / \mathrm{kg}$ of Zoletil (zolazepam/tiletamine; Virbac Labaratories, Carros cedex, France) in the femur of rats. A midline incision was made in abdominal wall and the superior mesenteric artery (SMA) was isolated without any damage to the peritoneal organs and blood vessels. In the IR and IR + selenium group, the isolated SMA was clamped with a bulldog clamp. Adequate blockage of SMA was confirmed by the color of the intestine turned pale (please refer to the figure in our previous report) [20]. To minimize water and heat loss, abdominal muscle and skin layers were then closed. After the 30 minutes of ischemic period, laparotomy was carried out again to restore SMA blood flow. The bulldog clamp was removed and reperfusion of the SMA was verified by the scarlet color of the small intestine. Abdominal muscle and skin layers were closed again. Then the animals were returned to their cages and allowed food and water ad libitum. All animals received $50 \mathrm{mg} / \mathrm{kg}$ of subcutaneous normal saline fluid after the procedures and no antibiotics were administered.

In the sham group, the clamping and declamping of the SMA were not performed. The IR + selenium group was administered selenium $(60 \mu \mathrm{g} / \mathrm{kg})$ and the sham and IR group were administered saline vehicle through a tail 
vein 24 hours before the procedures. The rationale to administer selenium at 24 hours before intestinal IR injury was based on the our previous study which showed therapeutic benefits of selenium at 24 hours after administration in paraquat intoxicated rats [12].

After the 30 minutes of ischemic period and the 90 minutes of reperfusion period, animals were sacrificed and oral buccal mucosa and small intestinal mucosa were harvested. Oral buccal mucosa of rats was obtained from both cheeks. Separated oral buccal mucosa and small intestinal mucosa were washed with phosphate buffered solution (PBS) for three times. After drying, those were frozen and stored in liquid nitrogen tank at $-70^{\circ} \mathrm{C}$ until required. Blood samples obtained by cardiac puncture were centrifuged at $2,000 \mathrm{~g}$ for $15 \mathrm{~min}$ at $4^{\circ} \mathrm{C}$, and separated sera were stored at $-80^{\circ} \mathrm{C}$ for subsequent assays.

\section{Measurements of GSH and GSSG levels, GPx activity, and MDA level}

Reduced glutathione (GSH) and oxidized glutathione (GSSG) levels in oral buccal mucosa and small intestinal mucosa were measured using a glutathione assay kit (Cayman Chem. Ann Arbor, MI, USA) [21]. Glutathione peroxidase (GPx) activity was measured using a glutathione peroxidase assay kit (Cayman Chem). Malondialdehyde (MDA) level was fluorometrically measured as 2 -thiobarbituric acid-reactive substance by the Ohkawa method [22,23].

\section{Nuclear and cytoplasmic extracts}

The extraction of nuclear and cytoplasmic proteins from oral buccal mucosa and small intestinal mucosa were performed using a NEPER nuclear and cytoplasmic extraction reagents kit (Pierce Chemical, Rockford, IL) [24]. Protein contents in the supernatant of the lysed mucosa were determined using a BCA protein assay reagent kit (Pierce Chemical).

\section{Western blot analysis}

To determine the expressions of cytoplasmic phosphor-

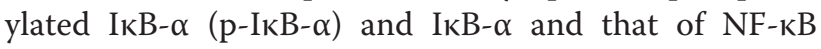
p65, we performed Western blotting as previously described [24]. In brief, nuclear and cytoplasmic extracts (10 $\mu \mathrm{g}$ per lane) were run on $8 \%$ and $12 \%$ sodium dodecyl sulphate-polyacrylamide gels, respectively, and then transferred to polyvinylidene difluoride membranes (Schleicher \& Schuell, Dassel, Germany). The following primary antibodies (Cell Signaling, Beverly, CA) were used for immunoblotting: rabbit antirat-p-IкB- $\alpha$ (1:250), ІкB- $\alpha$ (1:500), and NF-kB p65 (1:500) antibodies. As secondary antibodies, antirabbit immunoglobulin G (Stressgen, Victoria, BC, Canada) coupled with peroxidase and diluted 1:2000 in tris-buffered saline-Tween were used. Protein bands were detected by an enhanced chemiluminescence (ECL) system (Amersham International, Buckinghamshire, UK). Optical densities were quantified by a computer-assisted densitometric analysis of the exposed films (Lap Work Software; Seoulin Bioscience, Seoul, Republic of Korea). All blots were normalized against $\beta$-actin to control for protein loading. For $\beta$-actin measurements, the mentioned Western blot method was applied using a specific mouse monoclonal anti- $\beta$-actin antibody (Sigma-Aldrich, St.Louis, MO, USA).

\section{NF-кB P65 DNA-binding activity}

NF- $\kappa$ B p65 DNA-binding activity was determined using the TransAM method, and a NF- $\mathrm{kB}$ p65 transcription factor assay kit (Active Motif, Carlsbad, CA) was used to detect and quantify NF- $\mathrm{B}$ B transcription factor activation in oral buccal mucosa and small intestinal mucosa [25].

\section{Enzyme-linked immunosorbent assay}

Serum tumor necrosis factor- $\alpha$ (TNF- $\alpha$ ) level was measured using Duoset enzyme-linked immunosorbent assay kit (R\&D System, Minneapolis, MN). Enzyme-linked immunosorbent assay plates were measured using a Versa Max microplate reader (Molecular Devices Corp, Sunnyvale, CA) at $450 \mathrm{~nm}$ and concentrations of the respective proteins in serum were calculated according to calibration curves.

\section{Statistical analysis}

Data were analyzed by the Kruskal-Wallis with MannWhitney $U$ post hoc test and Bonferroni correction. $P$-values of $<0.017$ were considered statistically significant and the significance levels quoted are two-sided. Statistical analysis was conducted using SPSS version 12.0 for Windows (SPSS, Chicago, IL).

\section{Results}

\section{GSH and GSSG levels and GPx activity}

There were no significant differences in GSH and GSSG levels in oral buccal mucosa and small intestinal mucosa between the IR and IR + selenium groups. In both the oral buccal mucosa and small intestinal mucosa, however, GPx activity was higher in the IR + selenium group than in the IR group ( $p=0.004$ and 0.002 , respectively) (Table 1).

\section{MDA Level}

In the IR + selenium group, MDA level was lower than that in the IR group in both the oral buccal mucosa and small intestinal mucosa $(p=0.004$ and 0.002 , respectively) (Table 1).

\section{Cytoplasmic $p-І \kappa B-\alpha$ and І $к \mathrm{~K}-\alpha$ expressions}

In the IR + selenium group, cytoplasmic p-IкB- $\alpha$ expression in oral buccal mucosa and small intestinal mucosa 
Table 1 Laboratory results

\begin{tabular}{|c|c|c|c|c|c|c|}
\hline \multicolumn{7}{|l|}{$\mathrm{N}=6 /$ group. Median (range) } \\
\hline & \multicolumn{3}{|l|}{ Small intestine } & \multicolumn{3}{|c|}{ Oral buccal mucosa } \\
\hline & Sham & IR & IR + selenium & Sham & IR & IR + selenium \\
\hline GSH level (pmol/mg tissue) & $460(404-580)$ & $400(385-455)$ & $401(339-427)$ & $509(444-555)$ & $468(449-540)$ & $448(429-478)$ \\
\hline GSSG level (pmol/mg tissue) & $397(322-457)$ & $382(348-419)$ & $447^{\dagger}(418-467)$ & $387(337-438)$ & $354(321-399)$ & $392(360-416)$ \\
\hline GPx activity (mU/mg tissue) & $3.06(2.63-3.12)$ & $2.72(2.34-2.94)$ & $3.47^{* \mathbf{t}}(3.20-3.82)$ & $3.26(2.90-3.34)$ & $2.60^{*}(2.30-2.77)$ & $2.90^{\dagger}(2.76-3.16)$ \\
\hline MDA level (pmol/mg tissue) & $118(110-134)$ & $1113^{*}(849-1258)$ & $395^{* \boldsymbol{t}}(178-471)$ & $41(21-58)$ & $119^{*}(106-134)$ & $94^{* \mathbf{t}}(48-108)$ \\
\hline p-IkB-a expression (OD) & $1.00(0.53-1.28)$ & $1.87^{*}(1.49-2.50)$ & $1.06^{\dagger}(0.60-1.29)$ & $0.23(0.07-0.35)$ & $1.45^{*}(1.04-2.42)$ & $0.52^{\mathbf{\dagger}}(0.31-0.83)$ \\
\hline IkB-a expression (OD) & $1.00(0.88-1.28)$ & $0.22^{*}(0.12-0.44)$ & $0.92^{\dagger}(0.68-1.56)$ & $0.48(0.37-0.65)$ & $0.20^{*}(0.20-0.36)$ & $0.48^{\mathbf{t}}(0.32-0.58)$ \\
\hline NF-kB p65 expression (OD) & $1.00(0.78-1.70)$ & $17.40^{*}(9.93-17.69)$ & $3.77^{* \boldsymbol{t}}(3.63-4.62)$ & $0.33(0.08-0.59)$ & $8.44^{*}(7.15-9.93)$ & $2.32^{* \mathbf{t}}(1.73-3.16)$ \\
\hline \multirow[t]{2}{*}{ NF-kB p65 DNA-binding (OD) } & $1.00(0.90-1.23)$ & $2.65^{*}(1.80-2.93)$ & $1.62^{* \mathbf{t}}(1.20-2.03)$ & $0.47(0.47-0.50)$ & $0.59^{*}(0.54-0.67)$ & $0.51^{\mathbf{t}}(0.47-0.54)$ \\
\hline & \multicolumn{2}{|l|}{ Sham } & \multicolumn{2}{|l|}{$\mathbb{I R}$} & \multicolumn{2}{|l|}{ IR + selenium } \\
\hline Serum TNF-a level (pg/mL) & \multicolumn{2}{|l|}{$32.35(31.08-34.90)$} & \multicolumn{2}{|c|}{$226.60(183.46-330.04)$} & \multicolumn{2}{|c|}{$155.33(129.01-203.32)$} \\
\hline
\end{tabular}

GSH, Reduced glutathione; GSSG, Oxidized glutathione; GPX, Glutathione peroxidase; MDA, Malondialdehyde; $p$-I $K B$ - $a$, Phosphorylated inhibitor kappa B- $a$; NF- $K B$, Nuclear factor kappa B; IR, Small intestinal ischemia-reperfusion injury; TNF- $a$, Tumor necrosis factor a.

${ }^{*} p<0.017$ vs. the sham group. ${ }^{\dagger} p<0.017$ vs. the ischemic-reperfusion injury (IR) group.

was lower than that in the IR group $(p=0.008$ and 0.008 , respectively) (Figure 1). In contrast, cytoplasmic IKB- $\alpha$ expression was higher in the IR + selenium group than that in the IR group in both the oral buccal mucosa and small intestinal mucosa ( $p=0.016$ and 0.008 , respectively) (Figure 1).

\section{Nuclear NF-KB p65 expression}

In the IR + selenium group, nuclear NF-кB p65 expression was lower than that in the IR group in both the oral buccal mucosa and small intestinal mucosa $(p=0.008$ and 0.008 , respectively) (Figure 2).

\section{NF-KB p65 DNA-binding activity}

NF-кB p65 DNA-binding activity in oral buccal mucosa and small intestinal mucosa was also lower in the IR + selenium group than that in the IR group $(p=0.004$ and 0.009 , respectively) (Figure 3).

\section{Serum TNF-a level}

Serum TNF- $\alpha$ level in the IR + selenium group was significantly lower than that in the IR group $(p=0.009)$ (Figure 4).

\section{Discussion}

In the present study, we found that selenium pretreatment increased GPx activity, attenuated lipid peroxidation, downregulated the NF- $\mathrm{kB}$ pathway during small intestinal IR injury. Previous in vitro experiments have reported that oxidative stresses impair GPx to an inactive form and GPx activity has a primary role in the defense against oxidative stresses [26,27]. Our data also showed that small intestinal IR injury suppressed GPx activity and the increase of selenium-dependent GPx activity by selenium treatment contributed to attenuation of lipid peroxidation and downregulation of the NF- $k B$ pathway. Although the mechanisms of downregulation of the NF- $\mathrm{kB}$ pathway by selenium were not fully determined in this study, we suggest that increased GPx activity eliminates ROS and suppresses subsequent ROSdependent NF- $\mathrm{kB}$ activation. Since we did not use living tissues but frozen tissues, we were not able to measure ROS directly. We indirectly measured MDA level as a substitute for ROS. MDA has been known as a marker for lipid peroxidation by ROS. The decreased MDA levels in selenium treated rats in this study might be caused by the suppressed ROS formation, which support our suggestion.

In the present study, selenium treatment did not alter GSH or GSSG levels, which failed to show significant differences between the IR and selenium treated IR groups. Glutathione reductase reduces GSSG to GSH, and GPx oxidized GSH to GSSG. No change of GSH or GSSG levels in our study suggests that alternative mechanisms may be related to maintain GSH level regardless of increased GPx activity. Other previous data have shown that an adaptive response to ROS results in producing an increase in GSH level and the mechanism is associated with recovery of glutathione reductase activity or increased expression of $\gamma$-glutamylcysteine synthase $[28,29]$. Further studies which measure these enzymes will be needed to confirm our data.

Small intestinal IR injury occurs in the various medical conditions including necrotizing enterocolitis, midgut volvulus, intussusception, mesenteric ischemic disease, small bowel transplantation, aortic aneurysm surgery, cardiopulmonary bypass, hemodynamic shock, and sepsis. In the present study, therapeutic benefits of selenium were 


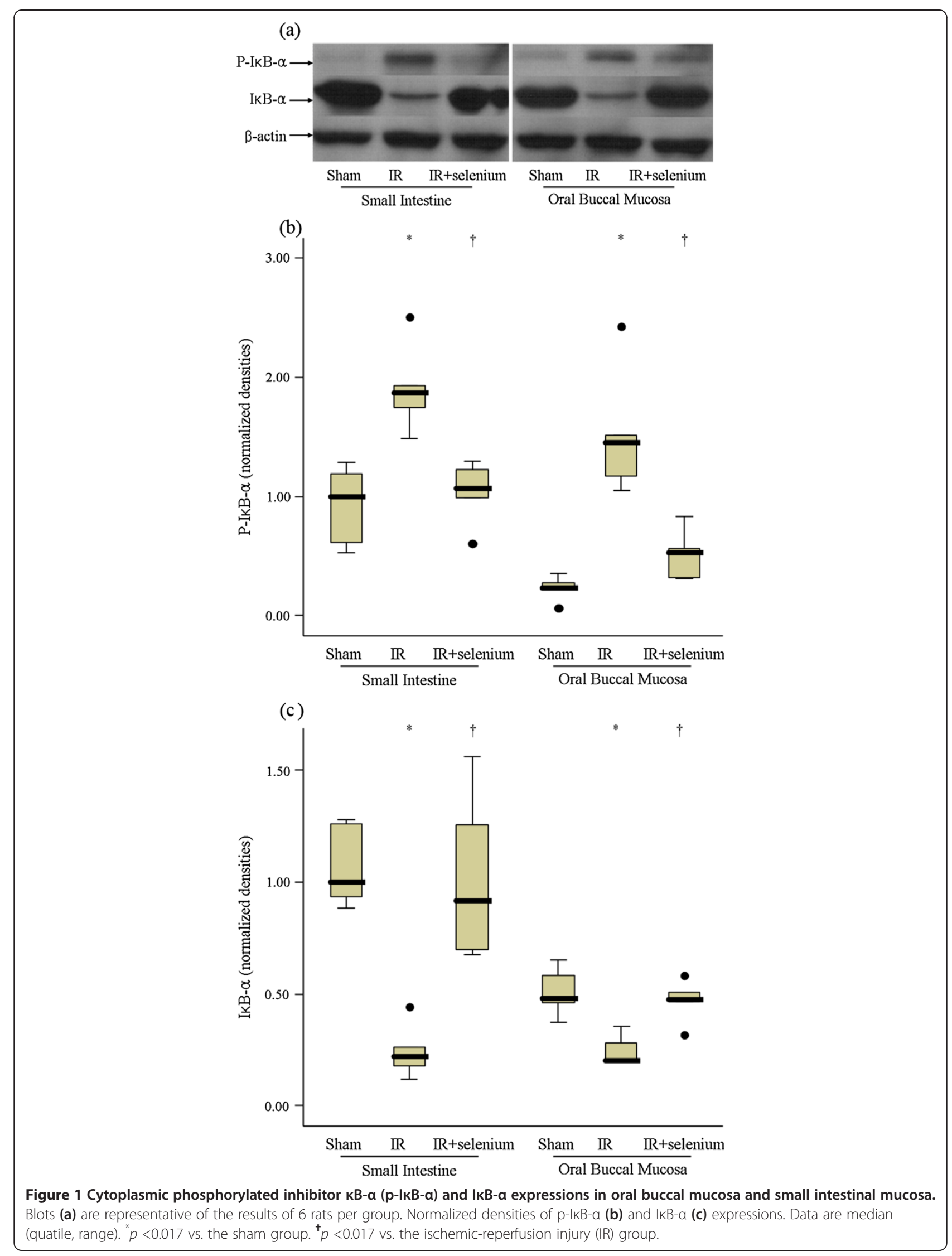




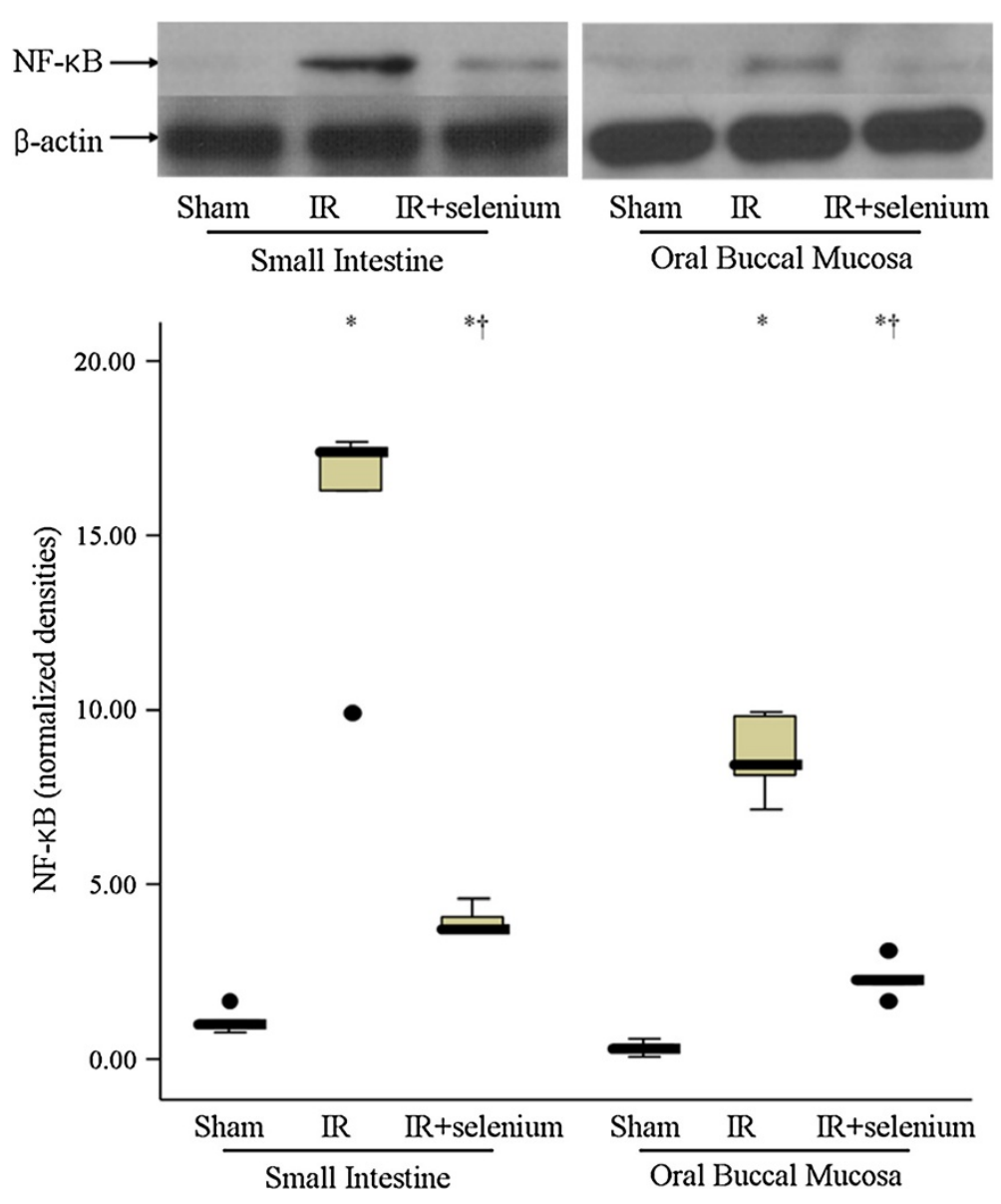

Figure 2 Nuclear NF-kB p65 expression in oral buccal mucosa and small intestinal mucosa. Blots are representative of the results of 6 rats per group. Data are median (quatile, range). ${ }^{*} p<0.017$ vs. the sham group. ${ }^{\mathbf{t}} p<0.017$ vs. the ischemic-reperfusion injury (IR) group.
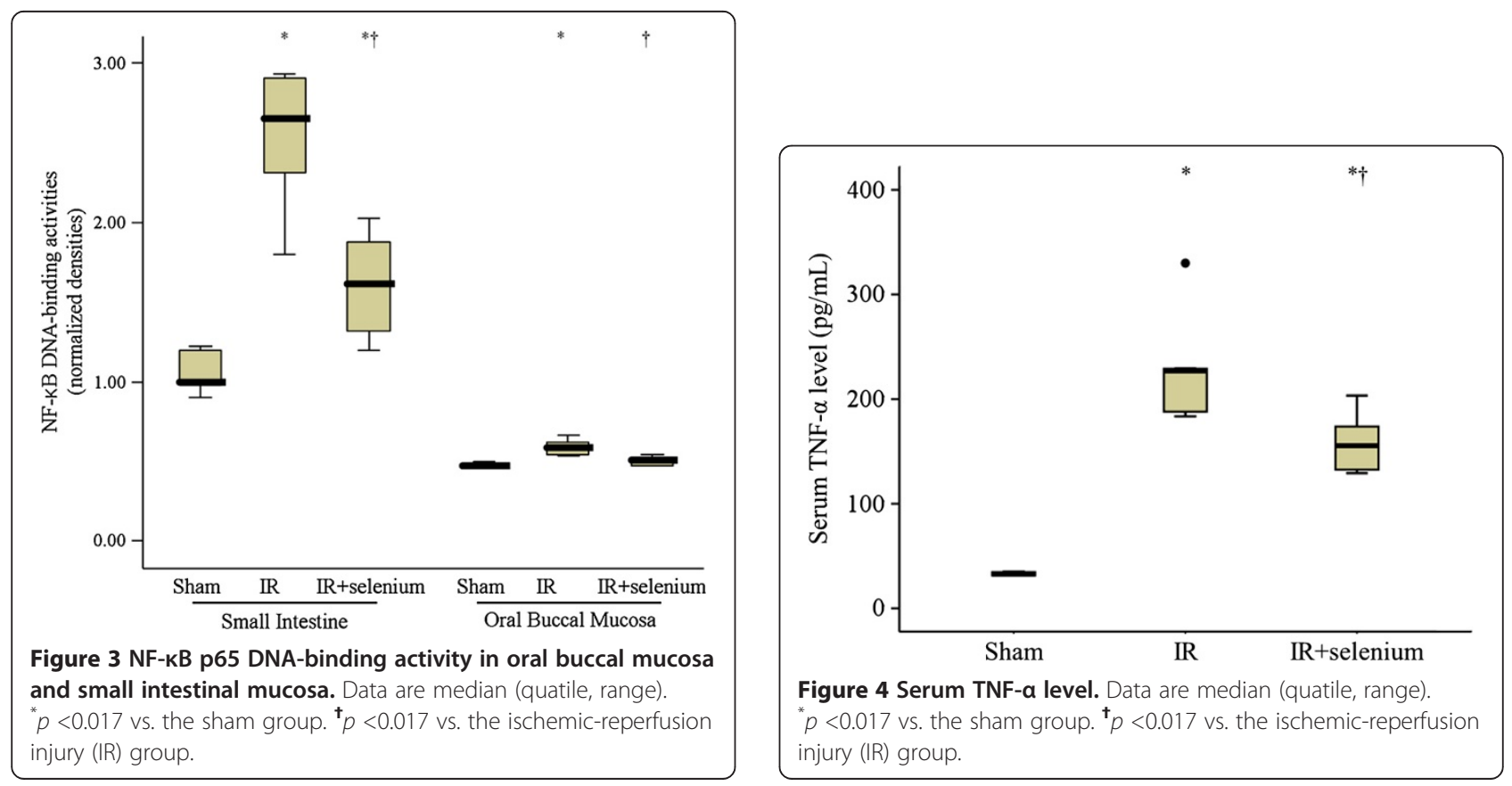
consistent in both the oral buccal mucosa and small intestinal mucosa. These results indicate that as a substitute for the intestinal mucosa, oral buccal mucosa can be used to detect the development of oxidative or inflammatory damages and to evaluate the beneficial effects of therapeutic agents in critically ill patients with small intestinal IR injury. In previous experimental data, we also found that NF-kB pathway was upregulated in both the oral buccal mucosa and the small intestinal mucosa during small intestinal IR injury [20]. These data indicate that antioxidant effects of selenium as well as oxidative stresses can be determined in oral buccal mucosa during small intestinal IR injury. However, the MDA level and NF-kB p65 DNAbinding activity of small intestinal mucosa were higher than those of oral buccal mucosa in the IR and selenium treated IR groups. These data suggest that the development of oral buccal mucosal injury is due to systemic inflammatory responses rather than direct IR injury.

Recent meta-analysis data suggest that high dose of selenium $(>500 \mu \mathrm{g} /$ day $)$ may improve the outcomes of critically ill patients, particularly dose at high risk of death [30-33]. Clinical trials of selenium supplementation have used a wide range of doses. In several studies, selenium was administered as an initial loading dose of $1000-2000 \mu \mathrm{g}$ and thereafter a continuous infusion of $1000-1600 \mu \mathrm{g} /$ day $[16,34]$. However, in two recent large randomized controlled studies (RCT), 500-800 $\mu \mathrm{g} /$ day of selenium were administered $[35,36]$. We infused a single dose of selenium $(60 \mu \mathrm{g} / \mathrm{kg})$. This dose of selenium in rats corresponds well to the doses used in the recent RCTs $[35,36]$. Furthermore, the human dose can be translated to experimental dose in rat by the body surface area normalization method $[37,38]$. The dose of selenium in rat would then range from 48 to $77 \mu \mathrm{g} / \mathrm{kg}$. Based on this calculation, we selected a $60 \mu \mathrm{g} / \mathrm{kg}$ as a clinically relevant dose. Clinically, it is so difficult to determine the adequate timing of selenium administration after small intestinal IR injury for the maximal antioxidant effect of selenium. The present study shows that the GPx activities can be measured in oral buccal mucosa, directly. Before its clinical use, further studies using more clinically relevant model should be performed.

In the present study, the amount of tissues of oral buccal mucosa was very small, and we failed to analyze tissue directly. An additional set of experiment for morphological tissue analysis is needed to confirm our data.

\section{Conclusion}

Selenium enhanced glutathione peroxidase activity, attenuated lipid peroxidation, and downregulated the NF$\mathrm{\kappa B}$ pathway during small intestinal ischemic-reperfusion injury. Furthermore, these therapeutic benefits of selenium seem to be observed in oral buccal mucosa as well as small intestinal mucosa.

\section{Abbreviations}

GPx: Glutathione peroxidase; GSH: Reduced glutathione; GSSG: Oxidized glutathione; IKB-a: Inhibitor kB-a; IR: Ischemia-reperfusion;

MDA: Malondialdehyde; MOF: Multiple organ failure; NF-kB: Nuclear factor $\mathrm{kB}$; PBS: Phosphate buffered solution; p-IKB-a: Phosphorylated IKB-a; ROS: Reactive oxygen species; SIRS: Systemic inflammatory response syndrome; SMA: Superior mesenteric artery

\section{Competing interests}

The authors declare that they have no competing interests.

\section{Authors' contributions}

Study concept and design: HKS and GJS, Acquisition of data: KYS and DCK, Analysis and interpretation of data: KYS and SOK, Drafting of the manuscript: KYS, ESC and SOK, Critical revision of the manuscript for important intellectual content: HKS, GJS and SOK, Statistical analysis: ESC and WYK, Administrative, technical or material support: ESC, DCK, SOK and WYK, Study supervision: GJS and HKS. All authors read and approved the final manuscript.

Received: 26 February 2014 Accepted: 21 October 2014

Published online: 30 October 2014

\section{References}

1. Stallion A, Kou TD, Miller KA, Dahms BB, Dudgeon DL, Levine AD: IL-10 is not protective in intestinal ischemia reperfusion injury. J Surg Res 2002, 105:145-152.

2. Carden DL, Granger DN: Pathophysiology of ischaemia reperfusion injury. J Pathol 2000, 190:255-266.

3. Yamamoto S, Tanabe M, Wakabayashi G, Shimazu M, Matsumoto K, Kitajima M: The role of tumor necrosis factor-alpha and interleukin-1 beta in ischemia-reperfusion injury of the rat small intestine. J Surg Res 2001, 9:134-141

4. Ceppa EP, Fuh KC, Bulkley GB: Mesenteric hemodynamic response to circulatory shock. Curr Opin Crit Care 2003, 9:127-132.

5. Pantano C, Reynaert NL, van der Vliet A, Janssen-Heininger YM: Redoxsensitive kinases of the nuclear factor-kappaB signaling pathway. Antioxid Redox Signal 2006, 8:1791-1806.

6. Gloire $G$, Piette J: Redox regulation of nuclear post-translational modifications during NF-kappaB activation. Antioxid Redox Signal 2009, 11:2209-2222.

7. Yao H, Yang SR, Kode A, Rajendrasozhan S, Caito S, Adenuga D, Henry R, Edirisinghe I, Rahman I: Redox regulation of lung inflammation: role of NADPH oxidase and NF-kappaB signalling. Biochem Soc Trans 2007, 35:1151-1155.

8. Kretz-Remy C, Arrigo AP: Selenium: a key element that controls NF-kappa B activation and I kappa B alpha half life. Biofactors 2001, 14:117-125.

9. Maehira F, Miyagi I, Eguchi Y: Selenium regulates transcription factor NF-kappaB activation during the acute phase reaction. Clin Chim Acto 2003, 334:163-171

10. Shenkin A: Selenium in intravenous nutrition. Gastroenterology 2009, 137:S61-S69.

11. Cheng W, Fu YX, Porres JM, Ross DA, Lei XG: Seleniumdependent cellular glutathione peroxidase protects mice against a pro-oxidant-induced oxidation of NADPH, NADH, lipids, and protein. FASEB J 1999, 13:1467-1475.

12. Kim KS, Suh GJ, Kwon WY, Kwak YH, Lee K, Lee HJ, Jeong KY, Lee MW: Antioxidant effects of selenium on lung injury in paraquat intoxicated rats. Clin Toxicol 2012, 50:749-753.

13. Ostadalova I, Vobecky M, Chvojkova Z, Mikova D, Hampl V, Wilhelm J, Ostadal B: Selenium protects the immature rat heart against ischemia/ reperfusion injury. Mol Cell Biochem 2007, 300:259-267.

14. Ozbal S, Erbil G, Koçdor H, Tuğyan K, Pekçetin C, Ozoğul C: The effects of selenium against cerebral ischemia-reperfusion injury in rats. Neurosci Lett 2008, 438:265-269.

15. Sakr Y, Reinhart K, Bloos F, Marx G, Russwurm S, Bauer M, Brunkhorst F: Time course and relationship between plasma selenium concentrations, systemic inflammatory response, sepsis, and multiorgan failure. $\mathrm{Br} J$ Anaesth 2007, 98:775-784.

16. Angstwurm MW, Engelmann L, Zimmermann T, Lehmann C, Spes $\mathrm{CH}$, Abel P, Strauss R, Meier-Hellmann A, Insel R, Radke J, Schüttler J, Gärtner R: Selenium in Intensive Care (SIC): results of a prospective randomized, placebo-controlled, multiple-center study in patients with severe 
systemic inflammatory response syndrome, sepsis, and septic shock. Crit Care Med 2007, 35:118-126.

17. Sonis ST: A biological approach to mucositis. J Support Oncol 2004, 2:21-32.

18. De Backer D, Creteur J, Preiser JC, Dubois MJ, Vincent JL: Microvascular blood flow is altered in patients with sepsis. Am J Respir Crit Care Med 2002, 166:98-104.

19. Elbers PW, Ince C: Mechanism of critical illness-classifying microcirculating flow abnormalities in distributive shock. Crit Care 2006, 10:221.

20. Kim SI, Kim YB, Koh KM, Youn YK, Suh GJ, Cho ES, Leem DH, Baek JA, Shin HK, Ko SO: Activation of NF-kB pathway in oral buccal mucosa during small intestinal ischemia-reperfusion injury. J Surg Res 2013, 179:99-105.

21. Ganji SH, Qin S, Zhang L, Kamanna VS, Kashyap ML: Niacin inhibits vascular oxidative stress, redox-sensitive genes, and monocyte adhesion to human aortic endothelial cells. Atherosclerosis 2009, 202:68-75.

22. Lee J, Kwon W, Jo Y, Suh G, Youn Y: Protective effects of ethyl pyruvate treatment on paraquat-intoxicated rats. Hum Exp Toxicol 2008, 27:49-54.

23. Ohkawa $H$, Ohishi N, Yagi K: Assay for lipid peroxides in animal tissues by thiobarbituric acid reaction. Anal Biochem 1979, 95:351-358.

24. Martins JO, Zanoni FL, Martins DO, Coimbra R, Krieger JE, Jancar S, Sannomiya P: Insulin regulates cytokines and intercellular adhesion molecule-1 gene expression through nuclear factor-kappaB activation in LPS-induced acute lung injury in rats. Shock 2009, 31:404-409.

25. Kwon WY, Suh GJ, Kim KS, Jo YH, Lee JH, Kim K, Jung SK: Glutamine attenuates acute lung injury by inhibition of high mobility group box protein-1 expression during sepsis. Br J Nutr 2010, 103:890-898.

26. Condell RA, Tappel AL: Evidence for suitability of glutathione peroxidase as a protective enzyme: studies of oxidative damage, renaturation, and proteolysis. Arch Biochem Biophys 1983, 223:407-416.

27. Blum J, Fridovich I: Inactivation of glutathione peroxidase by superoxide radical. Arch Biochem Biophys 1985, 240:500-508.

28. Shi MM, Kugelman A, Iwamoto T, Tian L, Forman HJ: Quinone-induced oxidative stress elevates glutathione and induces g-glutamylcysteine synthetase activity in rat lung epithelial L2 cells. J Biol Chem 1994, 269:26512-26517.

29. Cho S, Hazama M, Urata Y, Goto S, Horiuchi S, Sumikawa K, Kondo T: Protective role of glutathione synthesis in response to oxidized low density lipoprotein in human vascular endothelial cells. Free Radic Biol Med 1999, 26:589-602.

30. Alhazzani W1, Jacobi J, Sindi A, Hartog C, Reinhart K, Kokkoris S, Gerlach H, Andrews P, Drabek T, Manzanares W, Cook DJ, Jaeschke RZ: The effect of selenium therapy on mortality in patients with sepsis syndrome: a systematic review and meta-analysis of randomized controlled trials. Crit Care Med 2013, 41:1555-1564.

31. Manzanares W, Dhaliwal R, Jiang X, Murch L, Heyland DK: Antioxidant micronutrients in the critically ill: a systematic review and meta-analysis. Crit Care 2012, 16:R66.

32. Huang TS, Shyu YC, Chen HY, Lin LM, Lo CY, Yuan SS, Chen PJ: Effect of parenteral selenium supplementation in critically ill patients: a systematic review and meta-analysis. PLoS One 2013, 8:e54431.

33. Landucci F, Mancinelli P, De Gaudio AR, Virgili G: Selenium supplementation in critically ill patients: a systematic review and meta-analysis. J Crit Care 2014, 29:150-156.

34. Forceville X, Laviolle B, Annane D, Vitoux D, Bleichner G, Korach JM, Cantais E, Georges H, Soubirou JL, Combes A, Bellissant E: Effects of high doses of selenium, as sodium selenite, in septic shock: a placebo-controlled, randomized, double-blind, phase II study. Crit Care 2007, 11:R73.

35. Andrews PJ, Avenell A, Noble DW, Campbell MK, Croal BL, Simpson WG, Vale LD, Battison CG, Jenkinson DJ, Cook JA, Scottish Intensive care Glutamine or seleNium Evaluative Trial Trials Group: Randomised trial of glutamine, selenium, or both, to supplement parenteral nutrition for critically ill patients. BMJ 2011, 342:d1542.

36. Heyland D1, Muscedere J, Wischmeyer PE, Cook D, Jones G, Albert M, Elke G, Berger MM, Day AG, Canadian Critical Care Trials Group: A randomized trial of glutamine and antioxidants in critically ill patients. N Engl J Med 2013, 368:1489-1497.

37. Reagan-Shaw $S$, Nihal M, Ahmad N: Dose translation from animal to human studies revisited. FASEB J 2008, 22:659-661.

38. Center for Drug Evaluation and Research: Estimating the Maximum Safe Starting Dose in Initial Clinical Trials for Therapeutics in Adult Healthy Volunteers. Rockville, IL: Food and Drug Administration; 2005.

doi:10.1186/s12950-014-0036-1

Cite this article as: Kim et al:: Antioxidant and anti-inflammatory effects of selenium in oral buccal mucosa and small intestinal mucosa during intestinal ischemia-reperfusion injury. Journal of Inflammation 2014 11:36.

\section{Submit your next manuscript to BioMed Central and take full advantage of:}

- Convenient online submission

- Thorough peer review

- No space constraints or color figure charges

- Immediate publication on acceptance

- Inclusion in PubMed, CAS, Scopus and Google Scholar

- Research which is freely available for redistribution

Submit your manuscript at www.biomedcentral.com/submit
() Biomed Central 